\title{
SUS fora do rumo: busca de luzes: acima do SUS
}

\author{
SUS out of track: in search of light: beyond SUS
}

Nelson Rodrigues dos Santos ${ }^{\mathbf{1}}$

\section{Apresentação}

Iniciamos este artigo abordando, nos dois primeiros tópicos, o Sistema Único de Saúde (SUS) com testemunho e experiência na implantação dessa política pública: o tópico I trata da síntese das raízes do SUS e a persistência dos 'nichos' ou trincheiras e o tópico II, da construção da hegemonia 'anti-SUS'. Nos três tópicos seguintes, ousamos considerações pessoais no âmbito macro político, do qual basicamente depende o SUS: o tópico III aborda um olhar 'acima' do SUS, o tópico IV levanta os alertas nas reações da sociedade e o tópico $\mathrm{V}$ versa sobre o leite que derramou e a busca de luzes.

\section{Síntese das raízes do SUS e a persistência dos 'nichos' ou trincheiras}

\begin{abstract}
Abrimos esta síntese com a lembrança, hoje aparentemente ingênua, prosaica e superada, de que os valores humanos e sociais da solidariedade e do direito igualitário à saúde, somente 30 anos atrás empolgaram e mobilizaram o movimento municipal de saúde, o Movimento da Reforma Sanitária e a Assembleia Nacional Constituinte. E que geraram tanto uma vontade política hegemônica como o SUS no capítulo da Ordem Social na Constituição. A imagem-objetivo dessa lembrança foi o reconhecimento dos determinantes sociais e econômicos da
\end{abstract}

saúde e doença, e a possibilidade real de realização de Atenção Básica $(\mathrm{AB})$ à saúde para e com a população: acessível, de qualidade e no rumo de resolver 80 a $90 \%$ das necessidades de saúde, induzindo e alicerçando o reordenamento dos níveis assistenciais. Essa imagem-objetivo justificou o conjunto dos postulados constitucionais, comandados pela Universalidade, Integralidade, Equidade, Descentralização, Regionalização e Participação. Foi a lógica e as estratégias da democratização do Estado e construção do Estado de Bem-Estar Social, com políticas públicas universalistas para os direitos sociais básicos. Estratégias, essas, direcionadas para a regulação rigorosa das leis de mercado na saúde e aplicando os parâmetros social-democratas que orientam as políticas públicas de cidadania na Inglaterra, Canadá, na maior parte da Europa e outros países.

Contudo, a implementação dos postulados constitucionais de forma conjunta, estratégica e inovadora, ainda que gradativa desde os anos 1990, não vem sendo a regra, mas somente exceções que vêm perdendo para a real política pública do Estado brasileiro. Essas exceções vêm se desenvolvendo na 'base' do SUS em todo o território nacional via incontáveis experiências, esforços e aprendizados fortemente arraigados aos valores anteriormente citados e aos postulados da Constituição de 1988. São verdadeiros 'nichos' ou trincheiras de gestores municipais, de distritos de saúde, de Unidades Básicas de Saúde (UBS), de Núcleos de Apoio à Saúde da Família (Nasfs), de apoio 
matricial, de conselheiros municipais e locais de saúde, de trabalhadores de saúde, de equipes de saúde de família e outros no espaço da $A B$.

Lembramos também que essa persistência na 'base' do SUS deve-se, em grande parte, às raízes do movimento municipal de saúde que se inicia nos anos 1970 em periferias urbanas, junto às comunidades, realizando as primeiras tentativas de Atenção Primária à Saúde com base nos valores humanos dos direitos universais e com a visão estratégica de contribuir nos direitos sociais e na democratização do Estado. Desde seu início, esse movimento se amplia e ganha consistência com representações que participaram ativamente nos movimentos da reforma sanitária, como os simpósios nacionais de políticas de saúde da Câmara Federal (de 1979 e 1982), nos convênios com a previdência social Ações Integradas de Saúde (AIS) e Sistemas Unificados e Descentralizados de Saúde (Suds) -, na descentralização e municipalização das unidades estaduais de saúde e dos ambulatórios da previdência social, e por mais recursos públicos para a saúde. Resultou já com o SUS, na surpreendente extensão da cobertura populacional com inusitada produtividade nas ações e serviços de saúde, o que levou a incluir no sistema público de saúde metade da população brasileira, antes excluída de qualquer sistema.

As prefeituras municipais, desde os anos 1980, com recursos próprios e dos convênios com a Previdência Social, foram elevando vigorosamente os investimentos em UBS, serviços de urgência, policlínicas de especialidades, laboratórios e hospitais, o que se intensificou, nos anos 1990, com a responsabilidade de descentralização com ênfase na municipalização e com a criação dos conselhos de saúde na quase totalidade dos municípios - Leis 8.080/90 e 8.142/90 e, em número crescente, com conselhos de saúde locais e distritais. Dos 48 mil novos estabelecimentos públicos de saúde criados entre 1980 e 2005, 93\% são municipais, com salto de 43 mil para quase um milhão de servidores de saúde (de 16\% para $69 \%$ do total das três esferas de governo) nesse período. Congruentes com a assunção das novas responsabilidades constitucionais, os municípios foram elevando substancialmente seus recursos próprios para a saúde, com média nacional de $14,4 \%$ dos impostos municipais já no primeiro ano de aplicação da Emenda Constitucional 29 (EC-29), que estabeleceu o mínimo de $15 \%$ desses impostos, média essa que alcançou $23 \%$ em 2010, o que representou mais de dez bilhões ao ano no SUS além do mínimo e revelou que a esfera municipal vem sendo a única que rompe com a cultura política antipública e antissocial de tratar o 'mínimo' como ‘teto'.

Outros nichos ou trincheiras foram surgindo antes e com a implementação do SUS pelas três esferas de governo nas áreas da saúde mental (Centros de Atenção Psicossocial - Caps, luta antimanicomial), saúde do trabalhador (Centros Regionais de Saúde do Trabalhador - Cerests), controle da Aids, urgência/emergência, transplantes, hemocentros e vigilância em saúde; todos esses nichos e trincheiras, desenvolvendo excelência e expertise. Vejo-os como pontes voltadas para o futuro. Ao mesmo tempo em que demonstram irreversibilidade, nossos nichos ou trincheiras, não conseguem sair da exceção para a regra no volume do atendimento, no financiamento, no modelo de atenção e na qualidade. Por quê? Simultaneamente outras situações foram e são criadas.

\section{A construção da hegemonia 'anti-SUS'}

No início dos anos 1990, a política de Estado golpeou drasticamente o financiamento federal do SUS, descumprindo os $30 \%$ do orçamento da seguridade social para o SUS e retirando o Fundo Previdenciário da base de cálculo da parcela federal, o que reduziu essa parcela entre $1 / 2$ e $2 / 3$ do inicialmente 
indicado e consignado na Constituição e levou a drástico desinvestimento na rede pública hospitalar e ambulatorial de média e alta complexidade. Nos anos 1990, tal política exacerbou os contratos do SUS com prestadores privados de assistência especializada à saúde, pagos por produção, que, de complementares perante a Lei, passaram a substitutivos da rede pública, o que levou esse gasto federal a ser três vezes maior do que o da Atenção Básica, onde o piso variável se tornou várias vezes maior do que o piso fixo. Além disso, o pessoal de saúde dos prestadores públicos passou, em sua maior parte, para terceirizados precarizados, economizando a folha de pagamento. Também nos anos 1990, essa mesma política ampliou os subsídios ao mercado, com o cofinanciamento público de planos privados para todos os servidores e empregados públicos, além da ampliação da renúncia fiscal para pessoas físicas no âmbito da assistência, incluindo todos os trabalhadores formais do setor privado e sua estrutura sindical, outro duro golpe que arrefeceu a participação desses segmentos decisivos da sociedade na luta pelo SUS.

Em 1995, o Conselho de Secretarias Estaduais de Saúde (Conass) patrocinou oficina de trabalho com participação do Conselho de Secretarias Municipais de Saúde (Conasems), que reagiu ao impasse já evidente aos rumos do SUS, debateu e aprovou significativo relatório final apelando para a priorização da diretriz da regionalização, das redes regionais de atenção integral à saúde, com equidade, e com uma política pública de recursos humanos guiada pelas diretrizes constitucionais. A política de Estado desconsiderou esse relatório final, mas a gestão descentralizada do SUS ratificou o alerta e a proposição.

A partir de 1996, a política de Estado desviou a Contribuição Provisória sobre a Movimentação Financeira (CPMF), recém-aprovada para o financiamento do SUS, para outros dispêndios da União e criou a
Desvinculação das Receitas da União (DRU), que desvia $20 \%$ do orçamento da Seguridade Social também para outros dispêndios da União. A partir de 1998, essa política levou à Lei $9656 / 98$, que permite a aquisição de empresas nacionais de planos privados por capital estrangeiro (caso da Amil e Intermédica) e o descumprimento do ressarcimento ao SUS, previstos na mesma lei, pelos serviços públicos de saúde prestados aos consumidores de planos privados. Em 1998 e 2000, são criadas as Organizações Sociais (OS) e Organizações da Sociedade Civil de Interesse Público (Oscips), entes privados para gerenciar hospitais, ambulatórios e laboratórios públicos. Ainda em 2000, são limitadas drasticamente pela Lei da Responsabilidade Fiscal (LRF) as contratações na base do SUS, enquanto a EC-29 determina que somente os Estados, Distrito Federal (DF) e Municípios são obrigados a destinar percentagem mínima da sua arrecadação ao SUS (12\% para Estados e DF e 15\% para os Municípios). Estava claro, ao final dessa década, que a política de Estado que golpeia o SUS era nucleada nos Ministérios da Fazenda, da Casa Civil e do Planejamento, o 'núcleo duro' do Poder Executivo, articulado a lobbies poderosos instalados no Legislativo. Foram a lógica e a estratégia dominantes de desviar o rumo do Estado de Bem-Estar Social Universalista, constitucional, no campo das políticas públicas para os direitos sociais, para o rumo do Estado Neoliberal submisso ao mercado. Já ficava claro que a grande inclusão social pelo SUS estava no rumo do modelo de atendimento de demanda reprimida em todos os níveis assistenciais, de modo massivo, permanecendo o 'modelo SUS' ao nível dos nichos e trincheiras já referidos.

Em 2004, essa mesma política de Estado impede a vitória do histórico Projeto de Lei $n^{\circ} 1 / 2003$, que dispunha sobre o equivalente a $10 \%$ da Receita Corrente Bruta da União para o SUS, sobre os repasses federais equitativos e sobre a Regionalização. Na década 
de 2000, são atualizadas as isenções fiscais criadas pelo governo anterior sobre contribuições sociais aos hospitais privados, sofisticados, sem fins lucrativos mediante serviços especiais encomendados pelo Ministério da Saúde (MS), e se fomenta financiamento barato e facilitado para ampliação de hospitais privados e sofisticados de grande porte, bem como para a aquisição e construção de hospitais próprios das empresas de planos privados, inclusive pelo Banco Interamericano de Desenvolvimento (BID) e Banco Nacional de Desenvolvimento Econômico e Social (BNDES), dando continuidade aos duros golpes dos anos 1990 contra o SUS. Já ficava clara a estratégia de destinar a Atenção Básica de baixa resolutividade à população mais pobre e com caráter compensatório. Por outro lado, simultaneamente, nessa mesma década, a conjugação do salário mínimo acima da inflação com o Bolsa Família, o Benefício de Prestação Continuada, o 'boom' das commodities etc. levaram à ampla inclusão social com entrada no mercado de dezenas de milhões de novos consumidores, reativando o mercado interno e apontando para provável retomada do desenvolvimento. Opinaremos mais à frente sobre a relação dessa positiva e impactante inclusão via mercado, com a negativa estagnação e privatização nas políticas públicas constitucionais.

Em 2005, as entidades ligadas à reforma sanitária junto a parlamentares comprometidos com o PLP $n^{\circ} 1 / 2003$ promovem concorrido Simpósio Nacional de Política de Saúde na Câmara dos Deputados, que reforça espaço político para o Conasems e Conass protagonizarem, junto ao MS, o Pacto pela Vida, em Defesa do SUS e de Gestão (2006). O desafio da Regionalização é retomado no Pacto, junto aos $10 \%$ da Receita Corrente Bruta (RCB) para o financiamento federal. A Regionalização é articulada à construção da atenção integral, equitativa e intermunicipal, nivelando os sistemas municipais 'por cima', contemplando as diretrizes constitucionais e superando as tensões entre municípios vizinhos. Esse Pacto encontrou graves dificuldades de implementação perante a política de Estado (que negou o financiamento federal com o mínimo de $10 \%$ da RCB), mas criou espaço político para o debate, formulação e aprovação do Decreto 7508/2011 e da Lei 141/2012, ainda com sérias dificuldades de implementação.

Ao final da primeira década de 2000 , já se podia estabelecer provável relação entre a estratégia hegemônica na política pública e os imperativos da macroeconomia. De um lado, a soma dos recursos destinados ao setor privado complementar (substitutivo) e os gastos tributários destinados ao mercado dos planos privados e, de outro lado, o valor estimado dos recursos federais inicialmente indicados e consignados pela Constituição: este valor várias vezes maior do que aquela soma. Isto é, grande economia de gastos federais com o sistema público de saúde, valendo-se da privatização.

Em 2013, os golpes contra o SUS prosseguem: o governo federal (política de Estado) emite a PEC-358 (hoje, EC-86/2015) com base na Receita Corrente Líquida (RCL), o que retrai mais ainda a parcela federal no financiamento do SUS. Tal PEC constitucionaliza o subfinanciamento do SUS e desconsidera e atropela o Projeto de Lei de Iniciativa Popular (Plip) 321/2013, subscrito por 2,2 milhões de eleitores e dezenas de entidades da sociedade civil, que visava a resgatar o equivalente a $10 \%$ da RCB. Note-se que o Plip-321 elevaria o financiamento do SUS em apenas 0,8\% do PIB, isto é, de 3,9 para $4,7 \%$ do Produto Interno Bruto (PIB), enquanto os bons sistemas públicos em outros países contam em média com $8 \%$ do PIB. Esses $0,8 \%$ poderiam criar condição para viabilizar a retomada do rumo constitucional inicial, fortalecendo o apoio da sociedade e pressionando o Estado a priorizar o SUS. Ainda em 2013, o governo emite a MP-619, que amplia a renúncia fiscal para as empresas de planos privados sobre a Contribuição para o Financiamento da Seguridade Social 
(Cofins) e para o Programa de Integração Social (PIS).

Em 2014, essa política de Estado emite e aprova a MP-656, que legaliza (inconstitucionalmente) a abertura de toda a estrutura assistencial privada à aquisição pelo capital estrangeiro: trata-se de um 'filão de ouro' inicial de mercado contendo 55 a 60 milhões de consumidores de planos privados de saúde fortemente subsidiados por recursos públicos para assistência de média e alta densidade tecnológica. Trata-se, também, da etapa monopolista e globalizada da concentração do grande capital na assistência à saúde: as médias empresas comprando as pequenas, as grandes comprando as médias, conglomerando-se internacionalmente, submetendo os Estados Nacionais, regulando-os ao contrário de serem regulados. Esse 'filão de ouro' estende-se ao setor privado complementar no SUS, contratado ou conveniado pelo Estado. E entra em tramitação especial na Câmara dos Deputados a PEC-451/2014, que obriga os empregadores a incluir plano privado de saúde em todos os vínculos empregatícios dos trabalhadores urbanos $\mathrm{e}$ rurais, com renúncia fiscal a favor dos empregadores. Caso não fosse antecedida pelos duros golpes adotados contra o SUS em seus 25 anos, essa PEC, seguramente, sequer teria condições de tramitar no legislativo, devido ao peso político do SUS bem sucedido. Mas ao sucedê-los, faz coro com a lógica de o SUS ser apenas complementar aos trabalhadores sindicalizados urbanos, parte da baixa classe média, da média e da alta.

Como consequência final da estratégia hegemônica nos 25 anos do SUS, implementada pelo Estado, temos hoje a cobertura 'universal' segmentada: 25 a $30 \%$ da população que consome planos privados subsidiados, com per capita médio anual 'privado' três a quatro vezes maior que o baixíssimo per capita público 'SUS' para toda a população. Como esses 25 a 30\% utilizam os serviços e materiais do SUS em intensidade crescente, tanto na rotina como pelas ações judiciais individuais, seu per capita público é somado ao seu per capita 'privado', resultando num per capita quatro a seis vezes maior do que o dos 70 a $75 \%$ que não têm condições de comprar plano privado. A segmentação do acesso, qualidade e oferta evidencia-se também no conjunto dos consumidores: segmentos sociais com mensalidade entre 80 e 8.000 reais. Exemplo marcante dessa segmentação é o peso crescente dos idosos nos planos privados, compondo mais da metade dos consumidores: apesar do maior custo assistencial, a estabilidade dos aposentados resulta em maior adimplência com o plano privado de saúde (representando grande parte dos seus proventos) levando ao crescimento de empresas e planos voltados para os idosos. É um 'filão' de mercado atrativo para empresas estrangeiras. Ao golpear o SUS perante o crescimento dos idosos, a real política pública de saúde vem, inclusive, gerando dificuldade eleitoral nas disputas sindicais: a simples defesa do SUS retrai os votos nas urnas dos aposentados, eleitores de maior peso e sustentabilidade na entidade sindical. Essa cobertura 'universal' segmentada, construída em 25 anos, tripudia a Equidade, a Integralidade e o direito social: é o anti-SUS. O Estado Nacional, pelo menos na saúde, vem atuando como grande aparelho criador de mercado, dado que delega ao mercado uma responsabilidade constitucional republicana do Estado. O significado de cada um desses golpes no SUS e seu encadeamento nos 25 anos da sua existência é insofismável como grande indicador da política pública implícita (real), com lógica voltada para o mercado, fragmentação e iniquidade.

Em contraposição a essa política e estratégia hegemônicas, destacamos, além dos nichos e trincheiras anteriormente referidos, o surpreendente acervo de estudos, pesquisas e projetos acadêmicos de institutos de pesquisa e de colegiados gestores do SUS de larga consistência e aderência à construção do sistema público universalista e respeitabilidade técnico-científica (nacional e 
internacional) nos campos do financiamento, planejamento, gestão eficaz e eficiente, regulação, avaliação, modelo de atenção e relação SUS-sociedade. Símbolo desse acúmulo é o projeto Brasil-2030, coordenado pela Fiocruz em cooperação técnica com a Secretaria de Assuntos Estratégicos (SAE) e o Instituto de Pesquisa Econômica Aplicada (Ipea), com a publicação de consolidado inicial em 2012 de elevadíssimo nível. Nele constam diretrizes para prospecção estratégica do SUS no campo da macroeconomia e macropolítica para o horizonte 2022-2030 com 37 capítulos/pesquisas. A publicação ilustra três alternativas: a) otimista e possível, universalista, com relação público-privado claramente regulada pelo interesse e bem públicos, b) pessimista e plausível e c) inercial e provável. As duas últimas em diferentes formatos de 'mix público-privado' sob a hegemonia do mercado. Esse projeto avança com mais pesquisadores de alto nível, agora denominado Saúde Amanhã.

Não há sinal de tomada de conhecimento, menos ainda de reação e posicionamento pelos centros estratégicos de poder no Estado brasileiro sobre esse respeitável e consistente projeto, assim como dos demais similares. Contrasta com a repercussão midiática em meados de 2014 da entrega solene à Presidência da República do 'Livro Branco da Saúde', resultado de consultoria internacional da empresa Antares Consulting, contratada pela Associação Nacional de Hospitais Privados (ANAHP), com dez eixos estratégicos e doze propostas de conteúdo claramente vinculado aos interesses de mercado interno e externo da saúde, com discurso dúbio e inconsistente em relação à Universalidade, Igualdade e Integralidade.

Ao que nos consta, é estratégia oposta à das políticas públicas universalistas dos Estados de Bem-Estar Social da socialdemocracia europeia, canadense, costarriquense e várias outras. Tomando o setor saúde como indicador, é falsa a afirmação, de qualquer dos governos desde 1990 até nossos dias, de que tenha assumido estratégias no rumo de uma 'socialdemocracia brasileira'.

Podemos indagar: no Estado brasileiro, quais as estruturas e papéis que: a) no poder Executivo, formulam e constroem essa hegemonia? (incluindo a execução orçamentária federal real ao final de cada ano); b) no poder Legislativo, esvaziam ou distorcem seu dever constitucional de fiscalizar o Executivo no cumprimento das leis, assim como de refletir os anseios da sociedade, de legislar a soberania, os valores do bem comum, do bem público, dos direitos sociais e do desenvolvimento?; e c) no poder Judiciário, levam à evidente preferência pelas ações judiciais individuais mediante requisição médica para fornecimento pelo SUS de medicamentos, exames e materiais de médio e alto custo, impetradas por advocacia especializada, em detrimento de ações judiciais coletivas ou sociais ou de caráter realmente público, para cumprimento pelo poder Executivo dos postulados constitucionais, da legislação complementar e ordinária, no tocante aos direitos sociais e de cidadania?

De qualquer modo, parece-nos claro e insofismável que as incontáveis experiências, esforços, aprendizados, nichos e trincheiras referidos no primeiro tópico, de excelência e expertise no território nacional, que resistem e acumulam avanços à luz da Universalidade, Integralidade e Equidade, são decisivos para futura retomada estratégica e efetivação da hegemonia na construção conjunta de todos os postulados constitucionais. Hoje, as estatísticas anuais globais dos bilhões de ações na Atenção Básica, na média e alta complexidade, das centenas de milhões de exames diagnósticos, de duas centenas de bilhões de reais no financiamento, e outras, impressionam e impactam, mas a única comprovação positiva é a surpreendente capacidade produtiva dos trabalhadores de saúde no SUS, com tão poucos recursos públicos, que refletem a grande inclusão social no sistema público de saúde. Esses números de bilhões e milhões omitem o descumprimento das 
diretrizes constitucionais e da Lei Orgânica da Saúde voltadas aos direitos de cidadania. A regra que preside essas estatísticas é a do atendimento massivo de demanda duramente reprimida em todos os níveis assistenciais. $\mathrm{O}$ encadeamento e direcionamento dessa massa de financiamento e atendimento sob a lógica da Equidade e Integralidade na construção da Universalidade, ou seja, dos postulados constitucionais, é incompatível com as atuais estratégias hegemônicas na sociedade e no Estado. Por isso, a mera citação dessas estatísticas na mídia é, em regra, ufanista, camuflando grande parte do baixo ou nulo impacto na efetiva melhoria da saúde da população, e alega falsamente que falta mais gestão do que financiamento. Visa à falsa comprovação de que a Constituição está sendo cumprida na saúde, dado que age em contexto mais vinculado a mero projeto de poder do que de nação e sociedade.

Neste tópico, vale também registrar que a 'militância SUS' vem nos últimos anos avançando na formulação da implementação da diretriz constitucional da Regionalização, desafio fundamental da gestão pública. São encaradas as necessidades da população pela atenção integral e equitativa à saúde na região, incorporando os avanços municipais, intermunicipais e estaduais, sob as diretrizes nacionais tripartites com controle social. A priorização da elevação do financiamento anual federal estaria vinculada à priorização da implementação da Regionalização, tudo consignado em planos quinquenais aprovados em lei: a meta final é a implementação do 'modelo SUS', com a Atenção Básica resolvendo 80 a 90\% das necessidades de saúde, ordenando as redes regionais de cuidados integrais e o financiamento público por etapas, no rumo de $8 \%$ do PIB. Seria o planejamento competente e participativo, voltado para um real projeto de mudança e de futuro, com metas e cobrança de cumprimento.

Por isso, ainda neste tópico, insistimos que a retomada do rumo do SUS constitucional, incluindo a Regionalização com financiamento crescente, depende de uma 'militância acima do SUS' onde é disputada a hegemonia na sociedade e no Estado, que deve ser reforçada pela 'militância SUS'. A realização das conferências de saúde em 2015, as municipais, as estaduais e a nacional, seria uma oportunidade para esse elo.

A sociedade de hoje tem o direito inalienável de conhecer ou se apropriar do que está sendo feito com a política pública de saúde por ela construída e conquistada nos anos 1980, há mais de 25 anos, assim como debater democraticamente se quer manter a conquista e participar na construção do SUS universal de qualidade ou se quer continuar a 'cobertura universal segmentada nos serviços públicos e privados'. Pensamos que deva ser esse o eixo central dos debates na XV Conferência, e para que isso seja possível, viável e legítimo, esse processo democrático deve se iniciar desde já. Sugestões:

- Nos 25 anos do SUS, como os conselhos de saúde vêm realizando sua primeira atribuição legal?

- Como os conselhos de saúde, também em função da sua primeira atribuição, vêm atuando na desconstrução das estratégias anti-SUS?

- Como os conselhos de saúde vêm devolvendo, para a sociedade neles representada, os conhecimentos, resoluções e deliberações que neles se acumulam mensalmente? Cada conselheiro, nessa tarefa, perante sua entidade representada, é estimulado, orientado e acompanhado pelo conselho nessa missão?

- Como estão representados nos conselhos de saúde os 70 a $75 \%$ da população que dependem somente do SUS e os 25 a $30 \%$ que dependem do SUS e compram planos privados, todos, nas suas vidas cotidianas com necessidades, direitos e seus pleitos? 
- Desde 2013, crescem mobilizações e greves: por melhor transporte coletivo, de professores, de garis, de trabalhadores na saúde, de rodoviários, de metroviários, da polícia civil, de bombeiros, dos sem teto, dos PMs, dos sem terra, dos black blocs, de saqueadores, de depredadores e, em 2014 e 2015, da participação de segmentos conservadores, reacionários e golpistas. Sejam espontâneas ou organizadas, pacíficas ou violentas, sindicais ou de dissidências, manipuladas ou não, podem ser sintoma de tensão e mal estar social pela desigualdade e de esgotamento da política de Estado voltada quase que somente para a elevação da capacidade de compra do mercado. Constam nessas mobilizações bandeiras de maior responsabilidade para as políticas públicas de saúde, educação, transporte coletivo, segurança pública dentre outras. Estão consideradas para a XV Conferência?

\section{Um olhar 'acima' do SUS}

Efetivamente, as políticas e estratégias nacionais implementadas a partir de 2003 realizam:

a) impactante inclusão social, corrigindo o salário mínimo acima da inflação, desenvolvendo o Bolsa Família e interrompendo o desmanche, iniciado nos anos 1990, dos direitos trabalhistas e previdenciários (conquistas socialdemocratas do século XX);

b) reativação do mercado interno (ainda que predominando os ramos de baixa agregação de valor), que atenuou os efeitos da crise econômica global; e

c) expressivo impulso diplomático autônomo na política externa (2003 a 2010).
Essas políticas e estratégias acertadas compuseram os debates e bandeiras do amplo arco social e político debatido e articulado no decorrer do ano eleitoral de 2002 em torno de expectativas e esperanças de amplos segmentos excluídos, de trabalhadores, de grande parte das camadas médias e tendências sociais no espectro majoritário centrista e do centro-esquerda. Nesse cenário, constavam também expectativas sobre:

1) resgate das políticas públicas universalistas de qualidade (saúde-SUS, educação, segurança pública, transporte coletivo e demais direitos de cidadania);

2) redução e controle da insaciável transferência de recursos públicos em função dos juros elevadíssimos aos credores da dívida pública, como também do câmbio e do desenfreado desvio de recursos empresariais, do reinvestimento para o mercado de capitais, fatores da perniciosa desindustrialização em curso;

3) efetivo investimento de infraestrutura (energia, estradas, portos etc.) na industrialização com agregação de valor na qualificação das exportações (não dependência só de produtos primários); $\mathrm{e}$

4) efetiva adoção, pelo Estado, de condutas claramente éticas e republicanas de valores e práticas e sem a relação patrimonialista e venal entre o Executivo, Legislativo e o grande capital.

Ousamos sintetizar a imagem de que o conjunto das referidas políticas e estratégias, ainda que não debatidas em maior detalhe de projetos específicos no decorrer de 2002, indicava a clara vontade política da maioria da sociedade, no rumo da inclusão social com políticas públicas baseadas nos direitos de cidadania, e do desenvolvimento, no rumo de ruptura gradual com o capitalismo 
periférico dependente, refém da especulação financeira. Mais uma concepção e projeto de nação do que projeto de poder; mais um 'salto civilizatório' no rumo do Estado de Bem-Estar Social de cunho socialdemocrata, construído no século passado pelas sociedades da maioria dos países europeus, Canadá e outros, obviamente calcando em nossas realidades históricas, sociais e políticas. Diria que esse projeto, expectativa, esperança e a própria sociedade foram os grandes vencedores da eleição em 2002, sob a liderança e representação do $\mathrm{PT}$, partidos coligados e do ex-presidente Lula.

Contudo, a partir de 2003, ano a ano, com as políticas e estratégias citadas que integraram os debates e expectativas em 2002, verificou-se a implementação de a), b) e c), e a não implementação de 1), 2), 3) e 4). Em relação às quatro últimas, houve a reprodução das graves distorções herdadas dos anos 1990 e, em alguns aspectos, sua agravação, o que, por si, alimenta o crescente mal estar na sociedade, após vários anos de positiva sensação de rumo ao bem-estar conferida pelo sucesso da implementação das três primeiras. O orçamento da nossa Previdência Social continua superavitário, apesar da forte renúncia fiscal para 56 ramos empresariais, mas continua confiscado em $20 \%$ pela DRU, para fazer frente aos compromissos com os credores da dívida pública. Esse retorno real ao mal estar não pode nem deve ser minimizado pelo fato de estar sendo explorado e 'ampliado' midiaticamente pela militância e poder conservador neoliberal: não são necessárias maiores sofisticações de análise social, política e institucional para constatar, em crescentes segmentos sociais, a genuína frustação e decepção com a não implementação das quatro últimas políticas e estratégias citadas. É oportuno lembrar o estudo realizado em 2008 pelo Instituto Brasileiro de Planejamento Tributário comparando o Brasil, de elevada carga tributária, com a Inglaterra, França, Dinamarca, Espanha e Portugal, de cargas tributárias médias maiores ainda. No Brasil, a população trabalhava em média 117 dias no ano para poder comprar serviços privados de saúde, educação, previdência social, segurança pública e pedágio, e havia grande reação contra 'excesso de impostos'. Naqueles cinco países, os cinco serviços citados eram públicos e de qualidade e não havia reação da população contra impostos. Eram efetivamente mais republicanos e socialdemocratas. Cremos não exagerar ao lembrar que a geração que atuou para o fim da ditadura e nos debates constitucionais estava ainda presente e atuante nos debates eleitorais de 2002 junto à geração mais jovem e, por isso, contribuindo para o resgate da participação democrática em projeto de nação. Para melhor refletir sobre a não implementação de 1), 2), 3) e 4), ousamos tomar como uma das raízes determinantes o 'Presidencialismo de Coalisão', uma das imposições na transição da ditadura para a democracia no início dos anos 1980, que implicou o fortalecimento legislativo do Poder Executivo, submetendo o Poder Legislativo à condição predominantemente homologatória. Nos anos 1990, a aprovação do $2^{\circ}$ mandato governamental do Executivo, o instituto da Medida Provisória e a maioria das Emendas Constitucionais são alguns exemplos. Em troca da maioria governista no Congresso Nacional, ficou pactuada a prerrogativa do Legislativo, suas lideranças e partidos, para indicar a maioria dos ministros, direções das estatais, das agências reguladoras e operadores nos vários escalões da execução orçamentária federal. O perfil do Legislativo adequou-se ao número crescente de partidos (hoje, 32) sob a tutela do bloco majoritário (herdeiro da estrutura de apoio à ditadura) ou de arraigado clientelismo e fisiologismo, denominado 'centrão'. As coligações partidárias passaram a ser fortemente atreladas à cessão (venda) de tempo de rádio e TV, acesso ao fundo partidário e participação nos resultados (benesses) da execução do orçamento público para a compra de bens e serviços de empresas privadas, com 
poderosos lobbies atuando no Executivo e Legislativo. Um retrocesso, em aspectos básicos, ao patrimonialismo e clientelismo pré-republicanos. Esse presidencialismo de coalisão que perdura até hoje, como bem lembra Roberto Amaral,

vem impedindo a realização dos programas de campanha e de governo apoiados pelos eleitores e sociedade; levou a cidadania à orfandade político-partidária, esvaziou os partidos de valores e ideias-forças voltadas para um projeto de sociedade e aviltou o perfil do Legislativo e dos candidatos ao Legislativo. E acabou por revelar seu próprio esgotamento: mais que uma grave crise política, a sociedade está diante de uma crise republicana, que requer transformações na organização do Estado e do processo eleitoral. (AMARAL, 2015).

É nesse contexto do 'Presidencialismo de Coalisão’ que a implementação de 1), 2), 3) e 4) foi sendo postergada, com perdas para a sociedade e nação, a meu ver, inicialmente ofuscadas pelo sucesso da implementação de a), b) e c), com um ufanismo que se mostrou inconsequente. Com a crise internacional, em 2008, nosso governo adotou as mesmas medidas anticíclicas em 2009 e 2011 de reduzir, ainda que discretamente, a taxa Selic e os juros do BNDES e Caixa Econômica Federal (CEF) para manter o crédito, o que levou à forte reação do mercado rentista especulativo a partir de 2010, que, em aliança com o alto empresariado, aprofundou sua hegemonia e os altíssimos juros e lucros. De 2013 para 2014, enquanto estancavam a produção, os gastos públicos na área social e o PIB, o lucro das ações das grandes empresas na Bovespa quase dobrou, o lucro dos bancos cresceu perto de $30 \%$, o mesmo acontecendo para os rentistas da dívida pública.

Apesar do evidente acerto do ato governamental em reduzir a taxa de juros $(2009 \mathrm{E}$ 2011), perguntaríamos: por que só aplicado em 2009, como medida isolada de outras medidas políticas de um projeto de nação, ilustrados nos referidos 1), 2), 3) e 4)? Por que uma medida centralizada e vertical, sem debate, mobilização e suporte de amplos setores da sociedade? Perdeu-se o momento mais oportuno?

José Luis Fiori (2015A), em recente análise, se referiu com a acuidade e consequência de sempre ao novo projeto brasileiro no atual século, que alguns chamaram 'social-desenvolvimentista', formulado com base em coalisão liderada por forças progressistas, mas que foi se alargando até se tornar verdadeiro caleidoscópio ideológico e oportunista, visto que, na hora da desaceleração cíclica e do ajuste econômico a favor do sistema financeiro, a maioria dos 'aliados' desembarca da canoa com a mesma rapidez com que desembarcou do regime militar nos anos 1980 e da coalisão neoliberal nos anos 1990. E termina considerando que é também nessas horas de crise que podem ser tomadas decisões que mudem o rumo da história: com coragem, persistência e visão estratégica. Provocamos: o referido alargamento da coalisão liderada por forças progressistas terá produzido no seu interior, além da desaceleração do novo projeto brasileiro, também a cooptação de parte decisiva de lideranças e dirigentes dessas forças? Se parte das lideranças e dos dirigentes progressistas foi cooptada, onde está a maior parte que não se deixou cooptar, onde estão suas vozes e ações contra os cooptados e cooptadores?

\section{Alertas nas reações da sociedade}

Interessante ângulo para análise e reflexão sobre as expectativas e mobilizações na sociedade são a estratificação e a grande amplitude em nosso país das chamadas classes médias. Segundo a Pesquisa Nacional por Amostra de Domicílios (PNAD), do IBGE, de 2012 para 2013 a alta classe média caiu de $8,9 \%$ para $8,5 \%$ da população, a média classe 
média caiu de $15,6 \%$ para $14,3 \%$ e a baixa classe média subiu de $43,0 \%$ para $44,2 \%$; a massa trabalhadora caiu de $25,1 \%$ para $24,9 \%$ e os miseráveis subiram de $7,4 \%$ para $8,1 \%$. Waldir Quadros (2015) destaca a mobilidade descendente em cascata que afetou, em um ano, 5,7 milhões de pessoas, parecendo indicar o início de reversão do auspicioso ciclo de inclusão social iniciado em 2004. É uma complexa dinâmica que envolve as aspirações, o trabalho, os resultados e as frustrações dos assalariados dos setores público e privado, dos micro e médios empresários e dos profissionais autônomos (terceirizados ou não), dos estudantes e até de pequenos e médios rentistas: a grande maioria da população. Álvaro G. Linera (2003) alude à ultrapassagem da tradicional extração de mais valia na produção assalariada com o advento do neoliberalismo e o surgimento de uma 'proletarização difusa' entre assalariados dos setores público e privado, profissionais autônomos liberais, mini e micro empresários e empreendedores (terceirizados ou não), cientistas, pesquisadores, analistas, professores etc.

Outro interessante ângulo é o oportuno comentário de Clovis Rossi (2015), lembra-nos que as grandes manifestações de rua em nossa história recente tiveram forte predominância das classes médias: a marcha com Deus, Família e Propriedade em 1963, a marcha dos 100 mil no Rio de Janeiro em 1968, as manifestações dos trabalhadores no ABC paulista na dobrada dos anos 1970/1980, os atos pela anistia e as diretas já em 1983/1984, manifestações anti-Collor em 1992, posse do Lula em 2003, e as manifestações de 2013, 2014 e 2015 (completamos os exemplos). A grande fragmentação da sociedade e seus movimentos amplos desde 1990 até nossos dias, com a emergência do individualismo e corporativismo na ascensão social, e da consciência dos direitos do consumidor sobre a dos direitos de cidadania, justificam a assertiva que os manifestantes de 2013, 2014 e 2015 são 'filhos do atual capitalismo neoliberal de forte aspiração consumista individual'. Mas a grande amplitude, a heterogeneidade e o histórico das manifestações das nossas classes médias indicam que o seu conjunto responde por omissão, conivência, pró-ação ou reação às ações de uma parte que se mobiliza. Essa parte, em 1963 e na Av. Paulista (São Paulo) em 15 de março e abril, foi tipicamente conservadora, reacionária e golpista, e nos demais exemplos acima ilustrados foi tipicamente republicana e democrática. Há que serem consideradas a relação de forças econômicas, sociais e políticas, a trajetória e hegemonia da elite, as estratégias e rumos delineados na campanha de 2002, os reflexos recentes do nosso presidencialismo de coalisão, as influências conservadoras indutoras de movimentos trabalhistas menos sociais e mais corporativos, assim como o oportunismo de grupos, corporações e lideranças partidárias no seio do atual mal estar social.

Em junho de 2013, fortes manifestações de vários segmentos da sociedade surpreenderam pela expressa desconfiança nos políticos, partidos e governo estabelecido, da situação e oposição. Na repleta Av. Paulista, as principais bandeiras foram o transporte coletivo (passe livre) e os direitos básicos à saúde, educação, segurança pública e outros: com predominância dos jovens. Pesquisas de opinião revelam que $78 \%$ dos respondentes possuíam nível superior e $20 \%$, nível médio, e que $6 \%$ da população participaram das manifestações. Em 2014, no $2^{\circ}$ turno da acirrada campanha eleitoral, pesquisas de opinião revelavam que a grande maioria dos eleitores de cada uma das duas candidaturas finais coincidia os mesmos pleitos e bandeiras para o governo entrante: sem corrupção no Executivo e Legislativo e prioridade para os direitos básicos: emprego, salário mínimo, saúde, educação, segurança pública e outros. Eram também as bandeiras dos que votaram em branco ou anularam os votos, que, na apuração, somaram 37 milhões de eleitores. Em junho de 2013 e $2^{\circ}$ semestre de 2014, 
pensamos que importantes segmentos da sociedade e os eleitores estavam emitindo eloquentes sinais e alertas sobre o mal estar social, 'dando um recado' às representações políticas e ao governo. A reação a esse 'recado' foi de insensibilidade e desatenção: já no debate eleitoral, os marqueteiros de ambas as candidaturas concentraram-se só na radical desconstrução da imagem do (a) candidato (a) adversário (a) na mídia e redes sociais. Os temas centrais para a sociedade e eleitores, de ideias, valores, direitos e desenvolvimento de um projeto de nação ficaram em segundo plano ou foram desprezados. É bem possível que essa insensibilidade aos sinais e alertas da sociedade e eleitorado muito tenha contribuído para a manipulação pela mídia e redes sociais de uma polarização na sociedade, que, na verdade, encontra-se muito mais nos projetos de poder dos atuais políticos, partidos e governos, apesar da dispersão e despolitização processadas nos últimos 25 anos. De um lado pelos setores mais conservadores, reacionários e de sua mídia, que multiplicam o volume dos desmandos, corrupção e irresponsabilidade fiscal nos governos petistas, inclusive insinuando a privatização da Petrobrás, e, de outro lado, o establishment do PT, governo e quadros centrais de ambos, não reconhecendo: a) a continuidade dos desmandos e corrupção e de seu tamanho, doa a quem doer, e b) a desatenção aos pleitos e bandeiras da maioria da sociedade expressos nos sinais e alertas da sociedade em 2013 e 2014, que remontam às expectativas geradas na campanha de 2002.

Nas manifestações de 13 de março do corrente ano contra as medidas de mais cortes nos gastos sociais e de 15 de março contra os desmandos e corrupção, pesquisa de opinião (FERRAZ, 2015) mostrou que a 'polarização' assim expressou-se em cada uma:

- Democracia é sempre melhor: $86 \%$ e $85 \%$;
- Ditadura tanto faz ou em certos casos: $11 \%$ e $13 \%$;

- Congresso Nacional ruim ou péssimo: $61 \%$ e $77 \%$;

- Governo Dilma ruim ou péssimo: $26 \%$ e $96 \%$ (27\%, impeachment);

- Nível superior: $68 \%$ e $76 \%$;

- Preferiam o PT: $39 \%$ e preferiam o PSDB: 37\%;

- Eleitores de Dilma: $71 \%$ e eleitores de Aécio: 82\%;

- Renda até cinco salários mínimos: $62 \%$ e renda maior do que cinco salários mínimos: $68 \%$.

Na manifestação seguinte, em abril na Av. Paulista, 19\% dos manifestantes tinham renda acima de 20 salários mínimos, quando foram potencializadas as posições da manifestação de 15 de março.

Por final, seguem comentários sobre a nossa elite social, acima das classes médias, cujas reações como classe são menos visíveis, porém mais efetivas no conjunto da sociedade. A expressão absoluta da elite é do $1 \%$ mais ricos da população, objeto da impactante pesquisa de Thomaz Piketty (KRUGMAN, 2015), e, neste artigo, incluímos parte da alta classe média. Em meio à grave crise econômica e política do desvio criminoso, antissocial e antinacional de vultosos recursos públicos em nosso presidencialismo de coalisão, com divulgação de mais de $\mathrm{R} \$ 6$ bilhões desviados e mais de $\mathrm{R} \$ 20$ bilhões de prejuízo na Petrobrás, não podemos nem devemos atenuar a evidência do maior foco da crise nacional econômica e política. Referimos à galopante acumulação financeira especulativa que gera nossa monumental dívida pública, cujos juros, por volta de $\mathrm{R} \$ 220$ bilhões, 
amortização e refinanciamento, consomem 46 a $47 \%$ do Orçamento Geral da União, restando porcentagens irrisórias em orçamentos como: 3,8\% para a Saúde, $2,7 \%$ para a Educação e abaixo de $1 \%$ para Transporte, Energia e Segurança Pública. É dívida ao mesmo tempo assombrosa e blindada contra auditoria interna, externa, independente e revisão: seus poderosos detentores inculcam na sociedade que os gastos públicos com os credores e rentistas da dívida pública são um dogma virtuoso, mas os gastos públicos com direitos sociais e desenvolvimento são gastos perdulários a serem reduzidos. Esse foco central da crise está intimamente ligado à concentração da nossa riqueza e renda. Dados do Consórcio Internacional dos Jornalistas Investigativos sobre a Agência do HSBC na Suíça, ligada a paraísos fiscais (SuissLeaks), do Sindicato Nacional dos Procuradores da Fazenda Nacional ('Sonegômetro'), do Relatório de 2014 do Banco Credit Suisse, do Conselho Administrativo da Receita Federal (Carf), Conselho Administrativo da Receita Federal-Operação Zelotes, das Revistas Forbes e Exame, revelaram:

- 225 mil brasileiros possuem patrimônio acima de US\$ 1 milhão ( $\mathrm{R}$ 2,39 milhões);

- 230 mil brasileiros aplicam, cada um, acima de US\$ 1 milhão no mercado financeiro internacional;

- Era de brasileiros, em 2010, a quarta maior fortuna nos paraísos fiscais, estimada em US\$ 520 bilhões, ( $\mathrm{R}$ \$ 1 trilhão);

- É de brasileiros o quarto lugar de compradores de móveis em Miami, EUA;

- As 15 famílias mais ricas no Brasil concentram R \$ 270 bilhões, correspondentes a $5 \%$ do PIB;
- Havia, em 2006 e 2007, na filial suíça do HSBC, ligada a paraísos fiscais, 8.000 contas brasileiras, com desvios em 342 delas estimados em US\$ 7 bilhões. Não estão computados os valores muito maiores de empresas offshore montadas por brasileiros;

- Vultosos desvios de dívidas fiscais de grandes empresas brasileiras operados no Carf vêm sendo estimados em até R\$ 19 bilhões: Santander, Bradesco, Ford, Gerdau, Boston Negócios, Safra, Fiat e outras (A Gerdau já tem recurso contra a reposição de $\mathrm{R} \$ 5$ bilhões ao Tesouro Nacional); e

- Dados da Secretaria da Receita Federal - Ministério da Fazenda (MF) revelados no 'Sonegômetro' indicam dívida fiscal de $\mathrm{R} \$ 415$ bilhões em 2013, estimados em R $\$ 500$ bilhões para 2015.

Importante pesquisa do Instituto Federal Suíço, em 2011, revelou crescimento geométrico da concentração do capital: 147 superconglomerados com predominância do capital especulativo controlavam 1.318 conglomerados, detendo $40 \%$ da sua riqueza. Tais conglomerados, por sua vez, controlavam as 43 mil maiores corporações empresariais do mundo.

Esses dados, certamente sujeitos a variação a maior ou a menor, formam um conjunto que reflete o modo de participação de 296 mil brasileiros nos $1 \%$ mais ricos do mundo e de cinco milhões nos $10 \%$ mais ricos do mundo. Reflete a manutenção de $17 \%$ da renda nacional nas mãos do $1 \%$ mais ricos do País, assim como $75 \%$ da riqueza contabilizada com os $10 \%$ mais ricos. Reflete também, mais que a imunidade contra os efeitos da crise econômico-financeira, a sua própria gênese: basta observar quais estratos sociais e orçamentos públicos setoriais estão sendo tratados como perdulários e 'enxugados' pelo 
ajuste fiscal ora em andamento, entre $\mathrm{R} \$ 60 \mathrm{e}$ $\mathrm{R} \$ 80$ bilhões para bancar o superávit primário intocável da intocável dívida pública 'não perdulária'. Reflete ainda o recente encontro realizado no Waldorf Astória (Nova York), do qual participaram Bill Clinton, Fernando H. Cardoso, banqueiros, altos empresários e políticos, sobre o qual José Luis Fiori (2015B) refere plausível atualização do Consenso de Washington dos anos 1990. Reflete, enfim, a grande dificuldade de taxação das grandes fortunas e heranças, incluindo os valores mais tangíveis, como imóveis, ações e aplicações financeiras.

\section{O leite que derramou e busca de luzes}

Investigações oficiais comprovam que o destino criminoso, antissocial e antinacional de vultosos recursos públicos arrecadados (além dos sonegados), vem sendo impulsionado sob o 'presidencialismo de coalisão'. Revelam também que os correspondentes desmandos governamentais e corrupção continuam até nossos dias, ainda que sua divulgação venha sendo multiplicada, em relação aos governos do PT e coligados, pelos setores mais reacionários da sociedade e sua mídia. Essa continuidade é inadmissível, e sua avaliação, reconhecimento e enfrentamento são inabdicáveis e inadiáveis, sob pena de dispersão e esvaziamento da maior militância partidária da nossa história, o PT, além da massa de eleitores sem partido que aderiu ao debate de um projeto de nação na campanha de 2002.

A nosso ver, vai ficando claro que a exacerbação das reações pelos setores mais conservadores e reacionários da sociedade, políticos e mídia pode significar a revanche desses setores ante sua aparente defensiva e enfraquecimento perante uma 'onda petista' que se supunha mais consistente e consequente no governo nacional. É sabido que essa 'onda' crescia na oposição nos anos
1980 e 1990, assumindo radicalidade na denúncia e mobilização contra os desmandos éticos, econômicos e financeiros dos governos e partidos da situação. Repudiava, inclusive, a articulação de ampliação de forças políticas progressistas em direção a setores integrantes do 'centrão'. O apogeu da 'onda petista' iniciou-se na campanha eleitoral de 2002: o 'sonho petista' ampliou-se para o 'sonho das maiorias' na sociedade por outro projeto de nação com mais desenvolvimento e distributivismo. No tópico anterior, resumimos as expectativas e compromissos do ideário de 2002 em seus itens a), b) e c), cujo cumprimento repercute positivamente até hoje, e também nos itens 1), 2), 3) e 4 ), cujo descumprimento vem gerando mal estar social por si mesmo. Alguns analistas estendem sua preocupação a um provável peso negativo desse descumprimento, que, no médio prazo, certamente fragiliza o suporte político ao cumprimento dos itens a), b) e c), reduzindo-os, perante uma crise fiscal maior, a uma 'bolha de consumo' ou mera exploração de brechas nos espaços neoliberais do capitalismo dependente. Outros analistas lembram que, além do 'presidencialismo de coalisão', outro engendramento constou como imposição pétrea na transição da ditadura para a democracia: a canalização do movimento trabalhista e da estrutura sindical para uma alternativa exclusivamente 'trabalhista' imune a eventuais resquícios do 'pré-1964', o socialista e o 'brizolista'. Pensamos que esse engendramento, desenvolvendo-se nos anos 1990 e até nossos dias, exagerou a dose ajudando a descumprir os itens 1), 2), 3) e 4), abortando o projeto de nação. Mais recentemente, surge outra origem do mal estar social, que foi a continuidade do destino criminoso e antissocial de vultosos recursos públicos arrecadados além dos sonegados, comprometendo lideranças e dirigentes centrais de um partido de massas que sugeria imunidade ao fisiologismo, patrimonialismo, corrupção e projeto de poder pelo poder. 
Celso Barros (2015), em análise do recente congresso do PT, afirma que a recusa do afastamento dos dirigentes acusados de corrupção e consequente prestação de contas à população limitou drasticamente a possibilidade de o partido reconquistar o centro do espectro político para, então, rever e ampliar alianças, inovar estratégias perante as novas demandas da população emergente (dezenas de milhões) que as reformas pós-2003 fizeram aparecer na sociedade brasileira. Afirma, também, que, além da intocabilidade na aplicação regressiva dos impostos, dos esquemas políticos tradicionais e outras 'tradições' governamentais, os acordos de 2002/2003 mantiveram intocável o esquerdismo no PT na sua característica oposicionista dos anos 1990. Refere, ainda, que a recente Carta de Salvador daquele congresso, em seu ponto 44 , abre espaço de diálogo político entre as novas 'classes emergentes' com propostas do centro do espectro político, como: fundo público com forte progressividade na tributação e nos gastos, que ofereça acesso ao crédito, formação, tecnologia etc. para o mar de micros e pequenos negócios, assim como a volta à militância de base, à formação de frente com os aliados da esquerda etc. Ao que julgamos fundamental acrescentar o resgate das políticas públicas universalistas para os direitos sociais básicos expressos na Constituição de 1988.

Para o campo de conhecimento de políticas públicas e ciências políticas e sociais, penso caberem as questões: (i) até onde o histórico topo ou ápice da pirâmide de poder patrimonialista e colonizado dominante do Estado brasileiro combina-se em promiscuidade com os topos ou ápices das pirâmides do governo e partidos no Executivo e Legislativo? (ii) até onde essa combinação permeia a reprodução da hegemonia do capital financeiro desde os anos 1990 até hoje? (iii) há perspectivas de retomada do consenso construído em 2002, preferencialmente ampliado e mais explicitado?
Objetivando:

- A efetiva formulação de alternativas ao nosso capitalismo dependente periférico e ao jugo ilimitado e insaciável da acumulação especulativa do capital tem cabimento e espaço político potencial em nossos dias?

- Na atual conjuntura social e política, há espaço político potencial para a formulação de uma imagem-objetivo efetivamente socialdemocrata e de Estado de Bem-Estar Social desenvolvimentista?

- Na construção conjunta e pluralista desse espaço político, com a imprescindível transparência e ampliação nos debates, quais tendências partidárias, políticas, entidades e movimentos sociais, pensadores e intelectuais orgânicos, efetivamente comprometidos com a democratização do Estado reuniriam condições e estariam dispostos à implementação?

- Estando essa implementação voltada para a formulação e pactuação de um projeto de sociedade e nação, e, inevitavelmente, de poder, o pluralismo já mencionado teria condições de assumir efetivamente os poderes conquistados somente como meio de realização do projeto de sociedade e nação? $\mathrm{E}$, precipuamente, de manter a continuidade do debate do projeto entre si e com a sociedade, com as imprescindíveis verificações dos objetivos, meios e correções de percurso, ampliando e enriquecendo as pactuações?

- Na implementação da imagem-objetivo levantada na segunda indagação, por óbvio, todas as tendências alinhadas manteriam a prerrogativa democrática da disputa de poder na estrutura do Estado? E o próprio desenvolvimento 
do projeto de sociedade e nação, com participação direta da sociedade, balizará a dinâmica do papel e espaços de cada componente e tendência?

- Sob um espectro de valores e expectativas na sociedade, assim como ideias-força desde o centro até a esquerda, passando pelos vários matizes (mais plurais ou sectários) - corporativos, classistas, consumistas, religiosos e esquerdistas -, as maiorias estão interessadas no disposto na segunda e terceira indagação?

- O debate amplo e a implementação por etapas pactuados no disposto nas duas primeiras indagações são alternativas para reverter a hegemonia conservadora da direita, ilegitimamente implementada na mídia, Estado e sociedade? Apesar do domínio de nossa mídia por valores do individualismo, consumismo e especulação financeira, que embaçam e cerceiam o conhecimento do futuro real da sociedade e da nação, é possível disputar e furar esse bloqueio, visando disponibilizar para as massas sociais as informações e conhecimentos do que lhes diz respeito nos seus direitos, seu futuro e alternativas reais de desenvolvimento social?

- Que mudanças podem e devem ser implementadas desde já na reforma política, no quadro partidário, na democracia interna dos partidos e nos congressos de cada partido? Incluem a refundação de partidos e coligações?

- Nessa aliança ou coligação heterogênea, cada componente ou tendência em sua legitima militância, no seu espaço próprio, até onde manterá as pactuações e repactuações para o projeto comum de sociedade e nação avançar?
Multiplicam-se 'sinais' globais de esgotamento da atual hegemonia liberal especulativa, por exemplo:

a) James Galbraith, Universidade do Texas, acaba de lançar o livro 'The End of Normal the Great Crisis and the Future of Growth', onde denuncia o "uso excessivo de expressões matemáticas nos argumentos dos neoliberais sobre a perfeição dos mercados: usam a matemática para intimidar e não para esclarecer" (LUCENA, 2015A), e mostra alternativas para nova forma de o capitalismo manter sua sustentabilidade: substancial encolhimento do sistema financeiro, uso intensivo de mão de obra, robusto sistema de proteção trabalhista e social, custos fixos menores, baixas taxas de retorno e descentralização;

b) Martin Wolf, chefe do editorial do Financial Times, Londres, apologista nos anos 1980 e 1990 de Tatcher e Reagan, expõe que a austeridade fiscal falhou, a estabilidade financeira desapareceu, o atual modelo é ideal somente para os banqueiros e deve-se voltar à visão de Keynes (LUCENA, 2015B);

c) Rosa Maria Marques (2015), titular de economia na PUC-SP, defende que, no Brasil, fatias crescentes do lucro empresarial deixam de ser reinvestidas, passando a ser desviadas para a rentabilidade extraordinária do mercado financeiro (títulos, ações e derivativos), e que o investimento público, que sempre foi importante, é crescentemente desviado para os credores da dívida pública. Em escala mundial, o mercado financeiro já perfaz vários PIBs mundiais; $\mathrm{e}$

d) A conhecida pesquisa e projeções de Thomaz Piketty em escala mundial mostraram que, a partir do ano de 2016, os ganhos do $1 \%$ mais ricos no mundo 
superarão os dos restantes $99 \%$, o que acaba de ser confirmado pela respeitada ONG Oxfam (MELO, 2015).

Pensamos ser impossível visualizar a real diferença nos segmentos da nossa sociedade, desde os miseráveis à alta classe média, quanto às tensões das desigualdades, frustrações, revisões ou afirmações na conquista das aspirações, às confianças nas representações eleitas, e até mesmo nas diferenças entre os movimentos de rua desde 2013 e dos mais de $90 \%$ que ficaram em casa ou no trabalho etc. Mas somamos aos alertas e recados da sociedade: nas ruas em 2013, pelos eleitores (pesquisas de opinião) em 2014 que elegeram e os que votaram em branco ou anularam, e grande parte dos movimentos de 2015: emergem com força os não alinhados à situação e à oposição nos governos, nem às lideranças e partidos políticos, ou os mais céticos ou os mais esperançosos, os indignados em número crescente, e mesmo entre os alinhados, aqueles com crescentes reservas. Diríamos que se esgotaram os cenários e esperanças de disputa e exercício de poderes com base em promessas de que usaria o poder para o bem comum; crescem, paralelamente, as buscas de luzes e formulações de como o exercício do poder pode e deve ser reestruturado, democratizado e compelido a ser efetivamente controlado pela sociedade, e, nesse espaço, aí sim, se dar a disputa do poder.

$\mathrm{Na}$ Espanha, o movimento apartidário 'Indignados' cresce desde 2011, agora reforçado com o movimento 'Podemos', que já registrou para disputar eleições, entre várias bandeiras, a tolerância 'Zero' para corrupção e para os cortes orçamentários públicos orientados pelos objetivos da ganância e da especulação financeira. Nas recentes eleições municipais, ganharam a prefeitura de Madri (capital) e Barcelona ( $2^{\mathrm{a}}$ cidade). Cabe citar Juca Kfouri (2015), referindo-se a um dos Odebrecht: "Preferia que fosse diferente, mas o jogo é o jogo, não posso mudar o mundo", e Juca: "Todos podemos". Na Grécia, o Syriza foi fundado como movimento contra endividamento especulativo do País, registrou-se como partido e venceu eleições em oposição à coligação partidária que cumpria à risca a submissão a uma dívida pública crescente, juros altos, desestruturando a nação e regredindo a sociedade. Hoje é travada verdadeira guerra financeira do Fundo Monetário Internacional (FMI) e Banco Central Europeu, o gigante Gulliver, contra o governo e a população grega, o Pequeno Polegar. Junho passado, venceram 1,6 bilhões de euros de dívida que só pode ser paga com os salários e aposentadorias dos servidores. Além da Espanha e Grécia, correm em nossos dias buscas intensivas de alternativas ao domínio insaciável do capital financeiro especulativo, objetivando a construção de projeto de nação, a Noruega, Islândia, Irlanda e Bolívia. Itália e França estão no limite. É um conjunto diversificado de países em sua história, cultura e estrutura socioeconômica, porém, em comum, forçam uma relação mais participativa e reestruturante da sociedade em relação ao Estado na busca de um projeto de sociedade e nação não submisso à ditadura neoliberal financeira especulativa. Variam as composições no espectro centro-esquerda. Se há potencial de revés ou distorção, também haverá de adesão de mais sociedades e países a essas buscas.

A retomada do rumo inicial constitucional do SUS encontra-se sabidamente vinculada à reversão da atual política de Estado e também ao contexto macroeconômico nacional e global. Nessa reversão, a militância, somente no setor saúde, já se tornou quixotesca, mas, mesmo assim, imprescindível. Contudo, esse vínculo de solidez aparentemente incontornável pode, historicamente, diluir-se e revelar insustentabilidade. Referimos a possível vínculo com a práxis política da sociedade há quase 30 anos, informada, consciente e mobilizada para a possibilidade real de satisfação dos direitos humanos e sociais, que foram contemplados na Constituição cidadã de 1988. Essa possibilidade real encontra-se hoje espelhada na implantação da diretriz da 
Regionalização vinculada à elevação do financiamento federal e às formulações e pactuações dos gestores descentralizados, dos conselhos de saúde, das entidades ligadas ao Movimento da Reforma Sanitária e da população consciente e mobilizada, conforme já assinalado no segundo tópico deste artigo. Não é demais lembrar que a conscientização da população passa pela compreensão e postura de que os recursos públicos, após sua arrecadação, permanecem pertencendo à população, cabendo ao Estado administrá-los, investindo e custeando em benefício da população e nação. Esta obviedade vem, há décadas, sendo, na prática, obscurecida a favor de que só o que é comprado no mercado pertence ao consumidor. Ora, a consciência de que o SUS pertence a cada cidadão, e de que, sem consultá-lo, o Estado avilta o financiamento do SUS e subsidia fortemente os planos privados com os recursos públicos do cidadão, compelindo-o a satisfazer seus direitos consumindo no mercado, aí está um debate para cada segmento da sociedade: o do pertencimento. Daí, a bandeira 'Democratização do Estado'.

\section{Referências}

AMARAL, R. A Falência do Presidencialismo. Folha de S. Paulo. 30 abr. 2015. Disponível em: <wwwl.folha.uol. com.br/opiniao/2015/04/1622917-roberto-amaral-a-falencia-do-presidencialismo.shtml>. Acesso em: 30 jul. 2015.

BARROS, C. Um adeus ao lulismo. Folha de S. Paulo. [2015]. Disponível em: <http://wwwl.folha.uol.com.br/ fsp/ilustrissima/223377-um-adeus-ao-lulismo.shtml>. Acesso em: 30 jul. 2015.

FERRAZ, L. Maioria foi às ruas contra corrupção, diz Datafolha. Datafolha. 17 mar. 2015. Disponível em: <http://wwwl.folha.uol.com.br/ poder/2015/03/1603885-maioria-foi-as-ruas-contra-corrupcao-diz-datafolha.shtml>. Acesso em: 7 ago. 2015

FIORI, J. L. Ciclos e Crises. Carta Maior. 4 maio 2015a. Disponível em: <http://cartamaior.com.br/?/Coluna/ Ciclos-e-crises/33403>. Acesso em: 30 jul. 2015.

O caos ideológico. Carta Maior. 31 maio 2015b. Disponível em: <http://cartamaior.com.br/?/Coluna/Ocaos-ideologico-/33618>. Acesso em: 30 jul. 2015.
KFOURI, J. A tal da 'Neymardependencia'. Folha de $S$. Paulo. 18 jun. 2015. Disponível em: <http://wwwl.folha. uol.com.br/colunas/jucakfouri/2015/06/1644371-a-tal-neymardependencia.shtml >. Acesso em: 30 jul. 2015.

KRUGMAN, P. Livro 'O Capital no Século 21' revoluciona ideias sobre desigualdade. Folha de S. Paulo. 26 abr. 2014. Disponível em: <http://wwwl.folha.uol.com. br/mercado/2014/04/1445830-livro-o-capital-no-seculo-21-revoluciona-ideias-sobre-desigualdade.shtml>. Acesso em: 30 jul. 2015.

LINEIRA, A. G. Álvaro Garcia Linera: às esquerdas da Europa e do mundo. Carta Maior. 25 dez. 2003. Disponível em: <http://www.cartamaior.com.br/?/ Editoria/Internacional/alvaro-Garcia-Linera-as-esquerdas-da-Europa-e-do-mundo/6/29876>. Acesso em: 30 jul. 2015.

LUCENA, E. Crítica: Economista defende salários maiores e redução dos bancos. Folha de S. Paulo. 4 abr. 2015a. Disponível em: <http://wwwl.folha.uol.com. br/mercado/2015/04/1611278-critica-economista-defende-salarios-maiores-e-reducao-dos-bancos.shtml>. Acesso em: 30 jul. 2015. 
Crítica: Jornalista pede 'radicalismo' no combate à crise global. Folha de S. Paulo. 24 jan. 2015b. Disponível em: <http://wwwl.folha.uol.com.br/ mercado/2015/01/1579582-critica-jornalista-pede-radicalismo-no-combate-a-crise-global.shtml >. Acesso em: 30 jul. 2015.

MARQUES, R. M. 'O governo Dilma é totalmente refém do mercado'. Correio Cidadania. 30 jan. 2015. Entrevista concedida a Gabriel Brito. Disponível em: <http://www.correiocidadania.com.br/index. php?option $=$ com $\_$content $\&$ view $=$ article $\&$ id $=10464: \mathrm{m}$ anchete300115\&catid=34:manchete $>$. Acesso em: 30 jul. 2015.

MELO, R. O bruxo está solto. Folha de S. Paulo. 26 jan. 2015. Disponível em: <http://wwwl.folha.uol.com.br/ paywall/login-colunista.shtml?http://wwwl.folha.uol. com.br/colunas/ricardomelo/2015/01/1580333-o-bruxo-esta-solto.shtml>. Acesso em: 7 ago. 2015.

QUADROS. W. A regressão social que ameaça o Brasil. Le Monde Diplomatique. 3 maio 2015. Disponível em: $<$ http://www.diplomatique.org.br/artigo.php?id=1864>. Acesso em: 30 jul. 2015.

ROSSI, C. Classe média à la carte. Folha de S. Paulo. 14 abr. 2015. Disponível em: <http://wwwl.folha.uol.com. br/colunas/clovisrossi/2015/04/1616221-classe-media-a-la-carte.shtml>. Acesso em: 7 ago. 2015 